\title{
HUBUNGAN PENDIDIKAN SEKS YANG DIBERIKAN OLEH ORANG TUA DAN ATAU GURU DENGAN AKTIVITAS SEKS YANG DILAKUKAN REMAJA DI SMPN 22 KOTA BANJARMASIN
}

\author{
M. Mukhtar ${ }^{1}$, Hj. Erni Setiawati ${ }^{2}$, Hj. Norlena HD $^{3}$ \\ ${ }_{1,2,3}$ Politeknik Kesehatan Kemenkes Banjarmasin \\ Email: penelitian.poltekkes@gmail.com
}

\begin{abstract}
The Relationship of Sex Education Given by Parents and or Teachers with Sexual Activity by Adolescents in SMPN 22 Banjarmasin. Adolescence is transition period which activates hormone and sexual growth (Bigner, 2010). Study aimed relationship between sex education given by parents and or teachers with sexual activity by adolescents. Collecting data uses questionnaires. Population of SMPN 22 student is 401 people, sample is some of SMPN 22 students. It uses Purposive Sampling. Univariate and Bivariate analysis are used, through Chi Square test, significant value $\alpha=0.05$, trusted interval is $95 \%$. Result showed value of 0.054 . Conclusion there is no relationship between the sex education given by parents or teachers with sexual activity by adolescents in SMPN 22 Banjarmasin 2015.
\end{abstract}

Keywords: Sex education, Sexual activity, Adolescents

\begin{abstract}
Abstrak: Hubungan Pendidikan Seks yang Diberikan oleh Orang Tua dan atau Guru dengan Aktivitas Seks yang Dilakukan Remaja di SMPN 22 Kota Banjarmasin. Masa remaja masa transisi yaitu aktifnya hormon pertumbuhan dan seksual (Bigner,2010). Tujuan penelitian mengetahui hubungan pendidikan seks yang diberikan oleh orang tua dan atau guru dengan aktivitas seks yang dilakukan remaja. Pengumpulan data melalui kuesioner. Populasi siswa SMPN 22 berjumlah 401 orang, sampel sebagian siswa SMPN 22. Pengambilan sampel secara Purposive Sampling. Analisa yang digunakan Univariat dan Bivariat, melalui uji chi square, nilai kemaknaan $\alpha=0,05$, interval kepercayaan $95 \%$. Hasil penelitian didapatkan nilai 0,054 . Kesimpulan tidak ada hubungan antara pendidikan seks yang diberikan orang tua dan atau guru dengan aktivitas seks yang dilakukan remaja di SMPN 22 Kota Banjarmasin Tahun 2015.
\end{abstract}

Kata kunci: Pendidikan seks, Aktivitas seks, Remaja

Masa remaja merupakan masa transisi atau perubahan yang terjadi, terutama transisi fisik yaitu aktifnya hormon pertumbuhan dan hormon seksual (Bigner, 2010). Oleh karena itulah pentingnya pendidikan seks, agar para remaja terhindar dari aktivitas seks yang menyimpang . Pendidikan seks merupakan cara pengajaran atau pendidikan yang dapat menolong para remaja untuk mengatasi masalah yang bersumber pada dorongan seksual.

Sebaiknya pendidikan seksual diberikan pertama kali oleh orang tua, tetapi tidak semua orang tua mau terbuka terhadap anak dalam membicarakan masalah seksual. Tingkat sosial ekonomi maupun tingkat pendidikan yang berbeda menyebabkan ada orang tua yang mau dan mampu memberikan penerangan tentang seks tetapi lebih banyak yang tidak mampu dan memahami permasalahan tersebut (Gunarsa, 2007).

Pendidikan seks yang baik harus dilengkapi dengan pendidikan etika, pendidikan tentang hubungan antar sesama manusia, baik dalam hubungan keluarga maupun di masyarakat. Tujuan dari pendidikan seksual bukan untuk menimbulkan rasa ingin tahu dan rasa ingin mencoba hubungan seksual antar remaja, tetapi ingin menyiapkan agar remaja tahu tentang seksualitas dan akibat-akibatnya bila dilakukan tanpa mematuhi aturan hukum, agama dan adat istiadat serta kesiapan mental dan material seseorang (Husodo, 2011).

Menurut penelitian menyimpulkan bahwa kaum remaja di Indonesia mempunyai gaya hidup cendrung mengacu pada prilaku seks bebas (seks pranikah). Berikut ini penelitian-penelitian yang pernah dilakukan pada remaja pertama hasil penelitian DKT Indonesia (2005) membuktikan bahwa remaja secara terbuka menyatakan telah melakukan seks pra nikah di Jabodetabek (51\%), Bandung (54\%), Surabaya (47\%), Surabaya (47\%) dan Medan (52\%). Kedua menurut survei Komnas Perlindungan Anak di 33 provensi 2008 menyimpulkan $97 \%$ remaja SMP dan SMA 
pernah menonton film porno, 93,7\% remaja SMP dan SMA pernah ciuman, genital stimulation atau meraba alat kelamin dan oral seks, dan $62,7 \%$ remaja SMP dan SMA tidak perawan, serta 21,2 $\%$ remaja mengaku aborsi. Ketiga data PKBI tahun 2006 menunjukkan bahwa kisaran umur pertama kali melakukan hubungan seks pra nikah pada umur 13-18 tahun 60\% tidak menggunakan alat kontrasepsi dan yang sangat mengejutkan adalah 55\% dilakukan di rumah sendiri.

Berdasarkan data dari Dinas kesehatan Kota Banjarmasin, (Banjarmasin Post, Rabu 22 Pebruari 2012, Hal: 3) hingga akhir tahun 2011, ada peningkatan pada persalinan remaja, dari 50 orang pada tahun 2010, menjadi 235 orang pada tahun 2011. Pada kasus KTD (Kehamilan Tidak Diinginkan) termasuk aborsi di dalamnya, dari 35 orang pada tahun 2010 menjadi 220 orang pada tahun 2011.

Data tersebut berdasarkan acuan dari 26 Puskesmas sekota Banjarmasin, yang bekerja sama dengan Unit Kesehatan Sekolah (UKS) untuk jenjang SMP dan SMA dan telah dievaluasi Dinas kesehatan kata Diah Praswasti (Kepala Dinas Kesehatan Kota Banjarmasin). Lalu terkuaklah fenomena seks bebas itu.

Kepala Dinas Pendidikan Kota Banjarmasin, Hesly Juniato, sudah mendengar kabar tersebut. Namun validitas data perlu dikaji ulang, karena merupakan masalah yang sensitif. Guru dan orang tua harus lebih ketat mengawasi, begitu juga pengetahuan, agar mereka mengerti dan paham bahayanya kata Kepala Dinas Pendidikan Kota Banjarmasin tersebut.

Sesuai dengan studi pendahuluan yang dilakukan oleh peneliti, melalui wawancara singkat dengan Kapala Tata Usaha dan Wakil Kepala Sekolah SMP Negeri 22 Kota Banjarmasin, pada hari Sabtu Tanggal 10 Januari 2015. Mereka mengatakan bahwa siswanya tidak ada yang didapati melakukan aktivitas seks, seperti berciuman, melakukan hubungan seks dan sebagainya, namun ada siswanya yang keluar atau berhenti sebanyak 8 orang, karena tidak naik kelas. Keluar atau berhentinya 8 orang siswa tersebut, menurut penuturan Kepala Tata Usaha dan Wakil Kepala Sekolah, penyebab lain tidak mereka ketahui, apakah ada hubungannya dengan seks pranikah atau mereka kawin dan sebagainya.

Berdasarkan uraian tersebut di atas peneliti tertarik untuk melakukan penelitian dengan judul Hubungan Pendidikan Seks dengan Aktivitas Seks Remaja di SMP 22 Kota Banjarmasin Tahun 2015.

\section{METODE PENELITIAN}

Desain penelitian yang digunakan dalam penelitian ini adalah desain studi korelasional yaitu mencoba mengkaji hubungan antara variabel. Yaitu variabel pendidikan seks yang diberikan orang tua dan guru sebagai variabel independen yang dihubungkan dengan aktivitas seks sebagai variabel dependennya. Penelitian ini bertujuan untuk mengidentifikasi hubungan pendidikan seks yang diberikan oleh orang tua dan guru dengan aktivitas seks remaja di SMPN 22 Kota Banjarmasin.

Populasi dalam penelitian ini adalah seluruh remaja kelas VII, VIII dan IX di SMP Negeri 22 Kota Banjarmasin. Jumlah populasi adalah 401 orang.

Sampel adalah sebagian yang diambil dari keseluruhan objek yang diteliti dan dianggap mewakili seluruh populasi (Notoatmodjo, 2005). Teknik pengambilan sampel yang digunakan adalah Purposive Sampling yaitu pengambilan sampel yang didasarkan pada suatu pertimbangan tertentu yang dibuat oleh peneliti sendiri,

berdasarkan ciri atau sifat-sifat populasi yang sudah diketahui sebelumnya.

Menurut Soejono, 2005. Jumlah sampel ditetapkan dengan menggunakan rumus sebagai berikut :

$$
\begin{aligned}
& \mathrm{n}=\frac{\mathrm{N}}{1+\mathrm{N}(\mathrm{e})^{2}} \\
& =\frac{401}{1+401(0,1)^{2}}=4 \overline{401} \\
& \quad=\frac{401}{1+2}=\frac{401}{3}=133,66=134
\end{aligned}
$$

Keterangan :

$\mathrm{n}=$ Jumlah sampel

$\mathrm{N}=$ Populasi

$\mathrm{e}=$ Standar Error

Jadi jumlah sampel pada penelitian ini adalah 134 responden.

\section{HASIL}

\section{A. ANALISIS UNIVARIAT}

\section{Pendidikan Seks}

Berdasarkan tabel 1 dari 134 responden terdapat 123 orang (92\%) pendidikan seks diberikan orang tua dan atau guru, hanya 11 orang $(8 \%)$ pendidikan seks tidak diberikan. 
Tabel 1. Distribusi Frekuensi Responden Berdasarkan Pendidikan Seks yang Diberikan Orang Tua dan atau Guru

\begin{tabular}{crr}
\hline Pend Seks & f & \% \\
\hline Ya/diberikan & 123 & 92 \\
\hline Tidak & 11 & 8 \\
\hline jumlah & 134 & 100 \\
\hline
\end{tabular}

\section{Aktivitas Seks}

Berdasarkan tabel 2 dari 134 Responden terdapat 23 orang $(17 \%)$ yang melakukan aktivitas seks dan 111 orang $(83 \%)$ yang tidak melakukan aktivitas seks.

Tabel 2. Distribusi Frekuensi dan Persentase Aktivitas Seks Remaja

\begin{tabular}{lrr}
\hline Aktivitas seks & f & \% \\
\hline Ya/melakukan & 23 & 17 \\
\hline Tdk & 111 & 83 \\
\hline Total & 134 & 100
\end{tabular}

\section{B. ANALISIS BIVARIAT}

Tabel 3. Hubungan Pendidikan Seks yang Diberikan Oleh Orang Tua dan atau Guru dengan Aktivitas Seks Remaja

\begin{tabular}{|c|c|c|c|c|c|c|}
\hline \multirow[t]{3}{*}{ Pend seks } & \multicolumn{4}{|c|}{ Aktivitas seks } & \multirow{2}{*}{\multicolumn{2}{|c|}{ Total }} \\
\hline & \multicolumn{2}{|c|}{ Ya } & \multicolumn{2}{|c|}{ Tidak } & & \\
\hline & $\mathbf{f}$ & $\%$ & f & $\%$ & f & $\%$ \\
\hline Diberikan & 23 & 19 & 100 & 81 & 123 & 100 \\
\hline Tidak & 2 & 18 & 9 & 82 & 11 & 100 \\
\hline Jumlah & 25 & 19 & 109 & 81 & 134 & 100 \\
\hline
\end{tabular}

Berdasarkan tabel 3 dari 123 responden yang diberikan pendidikan seks oleh orang tua dan atau guru terdapat 23 responden yang melakukan aktivitas seks dan 100 responden yang tidak melakukan aktivitas seks. Kemudian dari 11 responden yang tidak diberikan pendidikan seks oleh orang tua atau gurunya, terdapat 2 responden yang melakukan aktivitas seks dan 9 responden yang tidak melakukan aktivitas seks.

\section{PEMBAHASAN}

Analisis hubungan pendidikan seks dengan aktivitas seks pada remaja Sesuai dengan hasil uji statistik dengan Fisher's Exact Test, didapatkan $p=0,155 \quad(\alpha=0,05)$, Artinya tidak terdapat hubungan yang bermakna antara pendidikan seks dengan aktivitas seks tersebut di atas dengan kata lain bahwa sebagian besar remaja SMPN 22 Kota Banjarmasin, yang pernah mendapatkan pendidikan seks dari orang tua atau gurunya, dengan berbagai aktivitas seks yang mereka lakukan, hampir sama dengan remaja SMPN 22 Kota Banjarmasin yang tidak pernah mendapatkan pendidikan seks sebelumnya. Tetapi bagaimana juapun dari berbagai aktivitas seksual yang dilakukan oleh remaja, ada berbagai faktor yang mempengaruhi, yaitu arus globalisasi yang semakin tidak terbatas, contoh kecil kasus forno grafi dan fornoaksi. Karena remaja pada umumnya mempunyai rasa ingin tahu yang tinggi, ini membuat remaja cendrung mencari tahu melalui VCD, buku, foto, majalah, internet, dan sumber-sumber lain yang belum tentu cocok untuk remaja. Sumber informasi yang didapat oleh remaja dapat memberikan substansi yang salah dan menyesatkan. Buku, majalah, film, dan internet yang mereka akses cendrung bermuatan pornografi, bukan pendidikan seks atau reproduksi.

Dari hasil penelitian ini dapat dipahami bahwa aktivitas seks yang dilakukan oleh remaja, hususnya remaja SMPN 22 Kota Banjarmasin dan remaja secara umum, banyak faktor yang mempengaruhi. Tetapi pendidikan seks pada remaja sedikit banyaknya tentu akan bermanfaat bagi remaja tersebut, hal ini sesuai dengan pendapat Sarwono (2010) yang mengatakan pendidikan seks adalah salah satu cara untuk mengurangi atau mencegah penyalahgunaan seks. Begitu juga dengan pendapat Asrofudin (2010) bahwa pendidikan seks bertujuan melindungi remaja dari berbagai akibat buruk karena persepsi dan aktivitas seks yang keliru. Pendidikan seks tetap harus diberikan sesuai dengan tingkat perkembangan anak, tujuannya selain apa yang sudah dikemukakan di atas juga memberikan bekal pengetahuan serta membuka wawasan anak-anak remaja seputar masalah seks secara benar dan jelas. Berarti seks yang benar menghindarkan mereka dari berbagai resiko negatif, seperti kehamilan di luar nikah, pelecehan seksual, dan penyakit menular seksual.

Pendidikan seks yang terbaik adalah yang diberikan oleh orang tua sendiri dan diwujudkan melalui cara hidup orang tua dalam keluarga sebagai suami isteri yang bersatu dalam perkawinan, dalam suasana akrab dan terbuka dari hati kehati antara orang tua dan anak. Oleh sebab itu orang tualah yang paling tepat untuk menyampaikan masalah pendidikan seks kepada anak-anak mereka. Pendidikan seks wajib diberikan orang tua sedini mungkin, tepatnya dimulai saat anak masuk play group atau usia 3-4 
tahun, karena pada usia ini anak sudah dapat mengerti mengenai organ tubuh mereka dan dapat dilanjutkan dengan pengenalan organ tubuh internal. Salah satu cara menyampaikan pendidikan seksual pada anak dapat dimulai dengan mengajari mereka membersihkan alat kelaminnya sendiri. Ajari anak untuk membersihkan alat genetalnya dengan benar setelah buang air kecil (BAK) maupun buang air besar (BAB), agar anak dapat mandiri dan tidak bergantung dengan orang lain. Dalam memberikan pendidikan seks pada anak jangan ditunggu sampai anak bertanya mengenai seks. Sebaiknya pendidikan seks diberikan dengan terencana, sesuai dengan keadaan dan kebutuhan anak. Sebaiknya pada saat anak menjelang remaja dimana proses kematangan baik fisik, maupun mentalnya mulai timbul dan berkembang ke arah kedewasaan.

\section{SIMPULAN}

Sesuai dengan hasil dan pembahasan maka penelitian ini dapat disimpulkan sebagai berikut :

1. Sebagian besar siswa SMPN 22 Kota Banjarmasin, yaitu 123 atau 92\% mengaku sudah pernah mendapatkan pendidikan seks dari orang tua dan atau gurunya, sedangkan 11 orang mengaku belum pernah mendapatkan pendidikan seks.

2. Sebagian besar siswa SMPN 22 Kota Banjarmasin, yaitu 99 atau $74 \%$ mengaku tidak pernah melakukan aktivitas seks dan 35 orang atau $26 \%$ pernah melakukan aktivitas seks.

3. Tidak ada hubungan antara pendidikan seks yang diberikan oleh orang tua dan atau guru dengan aktivitas seks yang dilakukan oleh siswa SMPN 22 Kota Banjarmasin.

\section{SARAN}

1. Agar pendidikan seks bagi siswa SMPN 22 tetap diberikan, lebih baik kalau bekerja sama dengan instansi-instansi yang terkait, seperti Dinas Kesehatan Kota atau Provinsi, Dinas Pendidikan Kota atau Provinsi, Pihak Kepolisian, BKKBN Kota Banjarmasin.

2. Hendaknya pihak sekolah juga memberikan pengetahuan kepada orang tua siswa tentang kesehatan reproduksi, mengingat masih ada siswa SMPN 22 Kota Banjarmasin yang tidak pernah mendapatkan pendidikan seks. Hal ini mungkin saja orang tua tidak mengerti manfaat kesehatan reproduksi atau pendidikan seks bagi anaknya.

\section{DAFTAR PUSTAKA}

Al- Mighwar Muhammad. 2006. Psikologi Remaja. Bandung: Pustaka Setia.

Athar, Shahid. 2004. Bimbingan Seks Bagi Kaum Muda. Jakarta: Pustaka Zahra.

Arikunto, Suharsimi. 2006. Prosedur Penelitian Suatu Pendekatan Praktik. Jakarta: Rineka Cipta.

Azwar, Saifuddin. 2011. Metode Penelitian. Yogyakarta: Pustaka Pelajar

Badan Koordinasi Keluarga Berencana Nasional. 2003. Penanggulangan Masalah Kesehatan Reproduksi. Jakarta.

BKKBN. 2005. Kesehatan Reproduksi Remaja. http/:www.BKKBN/2011.co.id (Diakses tanggal 20 Januari 2015).

Propinsi Jawa Tengah. 2006. Kesehatan Reproduksi Remaja.

Dariyo, Agoes. 2004. Psikologi Remaja. Bogor Selatan: Ghalia Indonesia.

Hidayat, A. Aziz Alimul. 2007. Metode Penelitian Kebidanan dan Teknik Analisis Data. Jakarta: Salemba Medika.
Erni. 2011. Pendidikan Seks Pada Remaja. Jurnalkes.poltekjkt@yahoo.co.id

Khoirotunnaviah, Lilis. 2011. Hubungan Pengetahuan dan Sikap Remaja tentang Hubungan Seksual Pranikah dengan Minat Remaja terhadap Hubungan Seksual Pranikah di SMA Ma'rif NU 04 Kangkung. Karya Tulis Ilmiah. D III Kebidanan FIKKES UNIMUS.

Notoatmodjo, Soekidjo. 2005. Metodelogi Penelitian Kesehatan. Jakarta: Rineka Cipta.

Sari Yuanita, Dra, 2011. Fenomena dan Tantangan Remaja Menjelang Dewasa. Yogyakarta: Briliant Books.

Sarwono, Sarlito W. 2011. Psikologi remaja. Jakarta: Charisma Putra Utama Offset.

Wijayanti. 2010. Gambaran umum dan prilaku remaja Tentang Seks Pranikah pada Pelajar SMA di Kota Semarang. Jawa Tengah: DEPKES Poltekkes Disertasi.

Wuryani, Sri Esti. 2008. Pendidikan Seks Keluarga. Jakarta: Indeks. 